\title{
EFFECTIVENESS AND TOXICITY DIFFERENCES BETWEEN THE USE OF REGIMEN CHEMOTHERAPY BLEOMYCIN-VINCRISTINE-MITOMYCIN-CISPLATIN AND BLEOMYCIN- VINCRISTINE-MITOMYCIN-CARBOPLATIN FOR THREE CYCLES IN PATIENTS CERVICAL CANCER SQUAMOUS CELL STADIUM IIB-IIIB IN SANGLAH GENERAL HOSPITAL DENPASAR BALI
}

\author{
NOVIYANI $\mathrm{R}^{1 *}$, SUWIYOGA $\mathrm{K}^{2}$, BUDIANA ING ${ }^{2}$, TUNAS $\mathrm{K}^{3}$, INDRAYATHI PA ${ }^{4}$
}

${ }^{1}$ Department of Pharmacy, Faculty of Mathematics and Sciences, Udayana University, Bali, Indonesia. ${ }^{2}$ Department of Obstetrics and Gynecology, Faculty of Medicine, Udayana University, Bali, Indonesia. ${ }^{3}$ Department of Public Health, Faculty of Health, Science and Technology, Dhyana Pura University, Bali, Indonesia. ${ }^{4}$ Department of Public Health, Faculty of Medicine, Udayana University, Bali, Indonesia. Email: rini.noviyani@gmail.com

Received: 09 June 2016, Revised and Accepted: 23 June 2016

\section{ABSTRACT}

Objectives: Medicines in the market need their security and their effectiveness monitored to ensure patient safety, which is called Clinical Testing Stage IV. Cytotoxic medicines especially those for cervical cancer chemotherapy, particularly need to be monitored. These medicines include two combinations: Bleomycin-vincristine-mitomycin-cisplatin (BOM-cisplatin) and bleomycin-vincristine-mitomycin-carboplatin (BOM-carboplatin). Both these combinations are commonly used for cervical cancer treatments in Sanglah General Hospital. Up till now, there has not been adequate data to differentiate between the two combinations. Therefore, we conducted the research to explore the relative effectiveness and toxicity of both combinations. The assessment of both combinations can be seen using parameter squamous cell carcinoma (SCC) and tumor-mass. Toxicity assessment of the chemotherapy can be seen by judging functions of the liver (serum glutamic oxaloacetic transaminase [SGOT], serum glutamic pyruvic transaminase [SGPT]), kidneys (blood urea nitrogen [BUN], creatinine), and blood (leukocytes, hemoglobin) of patients.

Methods: The observational research with the cross-sectional method in Obstetrics and Gynecology Clinics in Sanglah General Hospital Denpasar Bali. Research on both combinations was carried out between 2013 and 2015. The samples were obtained before the $1^{\text {st }}$ chemotherapy and after the $3^{\text {rd }}$ chemotherapy, by using consecutive sampling method. Prodia Clinical Laboratory carried out examinations on levels of SCC, while tumor-mass and the other parameters were carried out by Clinical Pathology Laboratory Sanglah General Hospital. Data were analyzed with the paired t-test with $95 \%$ confidence interval, using SPSS 17.0 for Windows.

Results: Samples used in this research was 12 patients who got combination BOM-cisplatin and 9 patients who got combination BOM-carboplatin. In the group of BOM-cisplatin, there is no difference of content of leukocytes, hemoglobin, creatinine, BUN, SGOT, SGPT, and SCC before the $1^{\text {st }}$ chemotherapy and after the $3^{\text {rd }}$ chemotherapy $\left({ }^{*} \mathrm{p}>0.05\right)$. However, there are different levels of tumor mass before the $1^{\text {st }}$ chemotherapy and after the $3^{\text {rd }}$ chemotherapy $\left({ }^{*} \mathrm{p}<0.05\right)$. In the group of BOM-carboplatin, there are no differences in the levels of Creatinine, BUN, SGPT, SGOT, tumor mass, and SCC $(* \mathrm{p}>0.05)$. However, there are different levels of leukocytes and hemoglobin $\left({ }^{*} \mathrm{p}<0.05\right)$.

Conclusion: The use of combination BOM-cisplatin can be said to be effective by the change of patients' tumor-mass after undergoing chemotherapy. The combination BOM-carboplatin is not effective because there were no changes in patients' tumor-mass and patients' levels of antigen SCC, and has toxic effects on patients' blood after undergoing chemotherapy.

Keywords: Effectiveness, Toxicity, Bleomycin-vincristine-mitomycin-cisplatin, Bleomycin-vincristine-mitomycin-carboplatin, Cervical cancer

(C) 2016 The Authors. Published by Innovare Academic Sciences Pvt Ltd. This is an open access article under the CC BY license (http://creativecommons. org/licenses/by/4. 0/) DOI: http://dx.doi.org/10.22159/ajpcr.2016.v9s2.13372

\section{INTRODUCTION}

Basically, all medicines that are distributed in the market have passed the Clinical Testing Stage III, where the potential of the medicine has been tested so it is with quality control and quality assurance [1]. The medicines that have been launched still need to be evaluated for their safety and effectiveness, namely, Clinical Testing Stage IV because many medicines in the market have a stronger side effect than therapeutic effect.

One of the medicines that has been marketed namely lumiracoxib, but after undergoing a Clinical Testing Stage IV apparently lumiracoxib can result in liver damage so that it was withdrawn from the market [2]. Besides that, other research also suggests that the use of Isotretinoin on a pregnant woman can cause problems in the fetus [3]. These medicines are non-cytotoxic but still have to go through the Clinical Testing Stage IV. Moreover, the medicines that are usually used for chemotherapy on cancer patients generally are cytotoxic.

Another study indicates that the use of regimen vincristine, cisplatin, and bleomycin used in chemotherapy for cervical cancer in stadium I-IV overall give an effectiveness marked by decreased antigens squamous cell carcinoma (SCC) levels and reduced tumor-mass on patients after undergoing three cycles of chemotherapy; however, the medicines cause a toxic side-effect such as myelosuppression [4]. Other research also suggests that the use of regimen paclitaxel-carboplatin inpatient cervical cancer (stadium IB-IIB) for three cycles caused a significant decrease in antigens SCC levels [5]. Other research also indicates the use of paclitaxel regimen, ifosfamide, and cisplatin give side effects such as neutropenia, anemia, and thrombocytopenia higher compared with ifosfamide and cisplatin [6]. Then a similar study also indicates that the use of cisplatin (dose more than $50 \mathrm{mg} / \mathrm{m}^{2}$ ) for 10 years may cause kidney damage [7].

Therefore, due to the side effects that are inevitable, it was necessary to monitor the medicines in the market so as to continue guaranteeing the safety of the medicines. Hence, we conducted the research to explore the relative effectiveness and toxicity of combination regimen bleomycin-vincristine-mitomycin-cisplatin (BOM-cisplatin) and combination regimen bleomycin-vincristine-mitomycin-carboplatin 
(BOM-carboplatin) for cervical cancer in Sanglah General Hospital Denpasar.

\section{METHODS}

The research was done in Sanglah General Hospital Denpasar after getting ethical clearance permission from the ethical commission research from Medical Faculty Udayana University. It is an observational research with the cross-sectional method in Obstetrics and Gynecology Clinics in Sanglah General Hospital Denpasar Bali. This method following up patients begins from the first chemotherapy to the third chemotherapy cycle. The data were undertaken before and after chemotherapy Cycle I and III. Selection of patients was based on the inclusion criteria such as new patients with cervical cancer type squamous cell stadium IIB-IIIB patients who are agree to follow up research by filling informed consent, clinical conditions, and laboratory results that fulfill the requirements to get chemotherapy, and patients that could make the entire range of chemotherapy Cycle I-III. Exclusion criteria of the research such as patients whose progress could not be followed for reasons such as patient death, financial problems, and could not be reached (lost-to-follow-up).

Data antigens SCC level and mass tumor measured before chemotherapy Cycle I and after chemotherapy Cycle III. Data serum glutamic oxaloacetic transaminase (SGOT), serum glutamic pyruvic transaminase (SGPT), creatinine serum, blood urea nitrogen (BUN), leukocytes, and hemoglobin measured before and after chemotherapy Cycle I, II, and III. Furthermore, all data obtained underwent a normality test first using Shapiro-Wilk test, then the data were analyzed by the difference paired $t$-test. The significant differences impact on antigens SCC value, mass tumor, serum creatinin, BUN, SGOT, SGPT, leukocytes, and hemoglobin in patients Before undergoing chemotherapy III cycles characterized by value $p>0.05$.

\section{RESULTS}

Samples used in this research was 12 patients who got combination BOM-cisplatin and 9 patients who got combination BOM-carboplatin. As shown in Tables 1-8, in the group of BOM-cisplatin, there is no difference of content of leukocytes, hemoglobin, creatinine, BUN, SGOT, SGPT, and SCC before the $1^{\text {st }}$ chemotherapy and after the $3^{\text {rd }}$ chemotherapy $\left({ }^{*} p>0.05\right)$. But there are different levels of tumor-mass before the $1^{\text {st }}$ chemotherapy and after the $3^{\text {rd }}$ chemotherapy $\left({ }^{*} \mathrm{p}<0.05\right)$. In the group of BOM-carboplatin, there are no differences in the levels of Creatinine, BUN, SGPT, SGOT, tumor-mass, and SCC $\left({ }^{*} \mathrm{p}>0.05\right)$. However, there are different levels of leukocytes and hemoglobin $\left({ }^{*} \mathrm{p}<0.05\right)$.

\section{DISCUSSION}

\section{Blood parameters}

Leukocytes and hemoglobin are the parameters commonly used to see any disturbance or a toxic effect that occurs in blood after chemotherapy is done [8]. Based on the statistics analysis using difference paired t-test in 12 patients who got chemotherapy BOM-cisplatin as shown in Table 1 and 2, the results found that there is no significant difference

Table 1: Result of the difference paired t-test data of leukocytes value before chemotherapy I and after chemotherapy III

\begin{tabular}{llll}
\hline \multirow{2}{*}{ Group } & \multicolumn{2}{l}{ Mean \pm Standard deviation } & \multirow{2}{*}{ p $^{*}$} \\
\cline { 2 - 3 } & $\begin{array}{l}\text { Before } \\
\text { chemotherapy I }\end{array}$ & $\begin{array}{l}\text { After } \\
\text { chemotherapy III }\end{array}$ \\
\hline BOM-cisplatin & $9.03 \pm 2.75$ & $7.37 \pm 4.55$ & 0.273 \\
BOM-carboplatin & $14.81 \pm 13.22$ & $9.54 \pm 13.96$ & 0.003 \\
\hline
\end{tabular}

Group BOM cisplatin: Based on statistical analysis as shown in Table 1, there is no significant difference of leukocytes value before chemotherapy I and after chemotherapy III $\left({ }^{*} p>0.05\right)$. The leucocyte value increase from 9.03 to 7.37 after third chemotherapy. Group BOM carboplatin: Based on statistical analysis as shown in Table 1, there is a significant difference of leukocytes value before chemotherapy I and after chemotherapy III $\left({ }^{*} \mathrm{p}<0.05\right)$. The leucocyte value decrease from 14.81 to 9.54 after third chemotherapy. in leukocytes $(* \mathrm{p}=0.273)$ and haemoglobin $(* \mathrm{p}=0.156)$ value before chemotherapy I and after chemotherapy III $\left({ }^{*} \mathrm{p}>0.05\right)$. While from 9 patients who got chemotherapy BOM-carboplatin as shown in Tables 1 and 2, there are significant differences value of leukocytes $\left({ }^{*} \mathrm{p}=0.003\right)$ and hemoglobin $\left({ }^{*} \mathrm{p}=0.035\right)$ before chemotherapy I and after chemotherapy III $\left({ }^{*} \mathrm{p}<0.05\right)$. This proves that the use of chemotherapy BOM-carboplatin gives a toxic effect for the blood. A toxic effect was due to use of mitomycin compounded by the use of carboplatin that can cause injuries in the spinal cord which result in anemia [9].

Depression of the bone marrow or spinal cord can be caused by toxicity of almost every kind of chemotherapy, marked by the decrease of the hemoglobin levels, leukocytes, the antenatal care, and platelets [10] Myelosuppression or depression of the spinal cord is because of the apoptosis on the hematopoietic stem cells (HSCs), replication change and improving death of HSCs and disruption of the stroma cells after undergoing chemotherapy so that the production of the blood cells decrease [11].

Statistically, the use of chemotherapy BOM-cisplatin does not show any difference, but clinically a decline in value leukocytes and hemoglobin before chemotherapy I and after chemotherapy III. Leukocytes mean value of the patient is $9.03 \mathrm{~g} / \mathrm{dl}$ before chemotherapy I and $7.37 \mathrm{~g} / \mathrm{dl}$ after chemotherapy III. While hemoglobin mean value, the patient is $10.83 \mathrm{~g} / \mathrm{dl}$ before chemotherapy I and $9.69 \mathrm{~g} / \mathrm{dl}$ after chemotherapy III. The decrease of the hemoglobin and leukocytes value of the patients that received chemotherapy regimen BOM-cisplatin shows depression to the spinal cord of patients due to the use of mitomycin and cisplatin that caused the process of blood cells formation to be diminished. Similar research indicates the use of chemotherapy etoposite and cisplatin caused leukopenia in lung cancer patients [12]. In another study, combination chemotherapy of cisplatin $100 \mathrm{mg} / \mathrm{m}$ and carboplatin $400 \mathrm{mg} / \mathrm{m}$ in patients with cervical cancer can cause the

Table 2: Result of the difference paired t-test data of hemoglobin value before chemotherapy I and after chemotherapy III

\begin{tabular}{llll}
\hline \multirow{2}{*}{ Group } & \multicolumn{2}{l}{ Mean \pm Standard deviation } & \multirow{2}{*}{$\mathbf{p}^{*}$} \\
\cline { 2 - 3 } & $\begin{array}{l}\text { Before } \\
\text { chemotherapy I }\end{array}$ & $\begin{array}{l}\text { After } \\
\text { chemotherapy III }\end{array}$ \\
\hline BOM-cisplatin & $10.83 \pm 2.82$ & $9.69 \pm 1.02$ & 0.156 \\
BOM-carboplatin & $12.52 \pm 1.71$ & $10.22 \pm 1.84$ & 0.035 \\
\hline
\end{tabular}

Group BOM cisplatin: Based on statistical analysis as shown in Table 2, there is no significant difference of hemoglobin value before chemotherapy I and after chemotherapy III $\left({ }^{*} \mathrm{p}>0.05\right)$. The haemoglobin value decrease from 10.83 to 9.69 after third chemotherapy. Group BOM carboplatin: Based on statistical analysis as shown in Table 2, there is a significant difference of hemoglobin value before chemotherapy I and after chemotherapy III $\left({ }^{*} \mathrm{p}<0.05\right)$. The haemoglobin value decrease from 12.52 to 10.22 after third chemotherapy. BOM: Bleomycin vincristine mitomycin

Table 3: Result of the difference paired t-test data of creatinin serum value before chemotherapy I and after chemotherapy III

\begin{tabular}{llll}
\hline Group & \multicolumn{2}{l}{ Mean \pm Standard deviation } & \multirow{2}{*}{$\mathbf{p}^{*}$} \\
\cline { 2 - 3 } & $\begin{array}{l}\text { Before } \\
\text { chemotherapy I }\end{array}$ & $\begin{array}{l}\text { After } \\
\text { chemotherapy III }\end{array}$ \\
\hline BOM-cisplatin & $0.71 \pm 0.12$ & $1.05 \pm 0.58$ & 0.068 \\
BOM-carboplatin & $2.63 \pm 5.03$ & $0.90 \pm 0.52$ & 0.335 \\
\hline
\end{tabular}

Group BOM cisplatin: Based on statistical analysis as shown in Table 2, there is no significant difference of hemoglobin value before chemotherapy I and after chemotherapy III $\left({ }^{*} \mathrm{p}>0.05\right)$. The creatinin value increase from 0.71 to 1.05 after third chemotherapy. Group BOM carboplatin: Based on statistical analysis as shown in Table 2, there is a significant difference of hemoglobin value before chemotherapy I and after chemotherapy III $\left({ }^{*} \mathrm{p}<0.05\right)$. The creatinin value decrease from 2.63 to 0.90 after third chemotherapy. BOM: Bleomycin vincristine mitomycin. 
occurrence of anemia, leukopenia, thrombocytopenia, hepatotoxicity, and nephrotoxicity [13].

\section{Liver parameters}

The liver is an organ in the human body that metabolizes a substance which is contained in the blood [8]. The parameters that can be assessed to determine the existence of a disorder in the function of the liver is using the SGOT and SGPT parameters [14]. The use of only SGOT value to see the liver damage by the effects of chemotherapy cannot be done, because secretion SGOT happened also in another organ. Therefore, to support SGOT value to see the liver damage than required an assessment of SGPT value in the body [15]. SGPT value is more specific indicated to the liver damage than SGOT value. This is because SGPT is only produced in the liver, so when there's damage to liver cells, SGPT value in the blood will increase [15]

Based on to statistical analyses as shown in Tables 5 and 6, using the difference paired t-test of 12 patients who received chemotherapy BOM-cisplatin obtained the result that there is no significant difference of SGOT $\left({ }^{*} \mathrm{p}=0.737\right)$ and SGPT $\left({ }^{*} \mathrm{p}=0.626\right)$ value before chemotherapy I and after chemotherapy III $\left({ }^{*} \mathrm{p}>0.05\right)$. Furthermore, from 9 patients who received chemotherapy BOM-carboplatin as shown in Tables 5 and 6 , the result found uthat there is no significant difference of SGOT $\left({ }^{*} \mathrm{p}=0.163\right)$ and SGPT $\left({ }^{*} \mathrm{p}=0.054\right)$ value before chemotherapy I and after chemotherapy III $\left({ }^{*} \mathrm{p}>0.05\right)$.

Statistically, the use of chemotherapy BOM-cisplatin and BOMcarboplatin show no significant differences in SGPT and SGOT value before and after chemotherapy but clinically a decline in mean value of SGPT from $13.14 \mathrm{U} / \mathrm{L}$ before chemotherapy I and become $12.32 \mathrm{U} / \mathrm{L}$ after chemotherapy III. However, the SGOT mean value rose from 17.27 U/L before chemotherapy I and became $17.77 \mathrm{U} / \mathrm{L}$ after chemotherapy III. While in patients receiving chemotherapy BOMcarboplatin seems to increase in mean value of SGPT and SGOT. SGPT

Table 4: Result of the difference paired t-test data of BUN value before chemotherapy I dan after chemotherapy III

\begin{tabular}{llll}
\hline Group & \multicolumn{2}{l}{ Mean \pm Standard deviation } & \multirow{2}{*}{$\mathbf{p}^{*}$} \\
\cline { 2 - 3 } & $\begin{array}{l}\text { Before } \\
\text { chemotherapy I }\end{array}$ & $\begin{array}{l}\text { After } \\
\text { chemotherapy III }\end{array}$ \\
\hline BOM-cisplatin & $9.76 \pm 5.34$ & $12.86 \pm 2.22$ & 0.128 \\
BOM-carboplatin & $10.55 \pm 3.69$ & $9.56 \pm 4.38$ & 0.566 \\
\hline
\end{tabular}

Group BOM cisplatin: Based on statistical analysis as shown in Table 4, there is no significant difference of BUN value before chemotherapy I and after chemotherapy III $\left({ }^{*} \mathrm{p}>0.05\right)$. The BUN value increase from 9.76 to 12.86 after third chemotherapy. Group BOM carboplatin: Based on statistical analysis as shown in Table 4, there is no significant difference of BUN value before chemotherapy I and after chemotherapy III $\left({ }^{*} \mathrm{p}>0.05\right)$. The BUN value decrease from 10.55 to 9.56 after third chemotherapy. BUN: Blood urea nitrogen, BOM: Bleomycin vincristine mitomycin

Table 5: Result of the difference paired t-test data of SGPT value before chemotherapy I and after chemotherapy III

\begin{tabular}{llll}
\hline Group & \multicolumn{2}{l}{ Mean \pm Standard deviation } & \multirow{2}{*}{ p $^{*}$} \\
\cline { 2 - 3 } & $\begin{array}{l}\text { Before } \\
\text { chemotherapy I }\end{array}$ & $\begin{array}{l}\text { After } \\
\text { chemotherapy III }\end{array}$ \\
\hline BOM-cisplatin & $13.14 \pm 4.12$ & $12.32 \pm 2.25$ & 0.626 \\
BOM-carboplatin & $18.01 \pm 9.85$ & $24.84 \pm 8.92$ & 0.054
\end{tabular}

Group BOM cisplatin: Based on statistical analysis as shown in Table 5, there is no significant difference of SGPT value before chemotherapy I and after chemotherapy III $\left({ }^{*} \mathrm{p}>0.05\right)$. The SGPT value decrease from 13.14 to 12.32 after third chemotherapy. Group BOM carboplatin: Based on statistical analysis as shown in Table 5, there is no significant difference of SGPT value before chemotherapy I and after chemotherapy III $\left({ }^{*} \mathrm{p}>0.05\right)$. The SGPT value increase from 18.01 to 24.84 after third chemotherapy. SGPT: Serum glutamic pyruvic transaminase, BOM: Bleomycin vincristine mitomycin mean value increased from $18.01 \mathrm{U} / \mathrm{L}$ before chemotherapy I to become 24.84 U/L after chemotherapy III. While SGPT means value increased from $19.82 \mathrm{U} / \mathrm{L}$, become 25.01 U/L after undergoing chemotherapy III.

An increase of the SGOT and SGPT value in patients receiving BOMcarboplatin occurred because of the use of platinum of carboplatin, and because of vincristine and mitomycin. Vincristine is one of the medicines that are metabolized by the liver and can cause hepatotoxicity when combined with radiation [16]. The use of carboplatin can also cause the hepatotoxicity that can be seen from elevated levels of SGOT and SGPT. Another study also mentions that the use of carboplatin can cause liver damage [17]. The use of mitomycin can also cause minor hepatotoxicity. This liver damage occurs because most of this medicine is lipophilic so it is easy to be taken up by the liver but not easily excreted. It may cause reactive oxygen formation products that are more dangerous than the original form itself causing irreversible hepatocellular [16].

\section{Kidney parameters}

The kidney is one of the organs that can be used to monitor a toxic effect that could be caused by chemotherapy. Secretion of cytotoxic drugs generally through the kidneys, where parameters that can be assessed to determine kidney function is the BUN and creatinine serum value [18]. Based on statistical analysis using the difference paired t-test as shown in Tables 3 and 4,12 patients who received chemotherapy BOM-cisplatin and 9 patients who received chemotherapy BOM-carboplatin shows that there are no significant differences in BUN $\left({ }^{*} \mathrm{p}=0.128 ;{ }^{* *} \mathrm{p}=0.566\right)$ and creatinine serum value $\left({ }^{*} \mathrm{p}=0.068 ;{ }^{* *} \mathrm{p}=0.335\right)$ of patients.

But clinically, there was an increase in BUN and creatinine serum value of patient who received chemotherapy BOM-cisplatin. BUN mean value before chemotherapy I was $9.76 \mathrm{~g} / \mathrm{dl}$ and became $12.86 \mathrm{~g} / \mathrm{dl}$ after chemotherapy III. Creatinine serum value before chemotherapy I was $0.71 \mathrm{~g} / \mathrm{dl}$ and $1.05 \mathrm{~g} / \mathrm{dl}$ after chemotherapy III. While there was a decrease in BUN and creatinine serum, mean value of patients who

Table 6: Result of the difference paired t-test data of SGOT value before chemotherapy I and after chemotherapy III

\begin{tabular}{llll}
\hline Group & \multicolumn{2}{l}{ Mean \pm Standard deviation } & \multirow{2}{*}{$\mathbf{p}^{*}$} \\
\cline { 2 - 3 } & $\begin{array}{l}\text { Before } \\
\text { chemotherapy I }\end{array}$ & $\begin{array}{l}\text { After } \\
\text { chemotherapy III }\end{array}$ & \\
\hline BOM-cisplatin & $17.27 \pm 4.82$ & $17.77 \pm 2.87$ & 0.737 \\
BOM-carboplatin & $19.82 \pm 5.49$ & $25.01 \pm 12.17$ & 0.163 \\
\hline
\end{tabular}

Group BOM cisplatin: Based on statistical analysis as shown in Table 6, there is no significant difference of SGOT value before chemotherapy I and after chemotherapy III $(* \mathrm{p}>0.05)$. The SGOT value increase from 17.27 to 17.77 after third chemotherapy. Group BOM carboplatin: Based on statistical analysis as shown in Table 6, there is no significant difference of SGOT value before chemotherapy I and after chemotherapy III $(* \mathrm{p}>0.05)$. The SGOT value increase from 19.82 to 25.01 after third chemotherapy. BOM: Bleomycin vincristine mitomycin, SGOT: Serum glutamic oxaloacetic transaminase

Table 7: Result of the difference paired t-test data of tumor-mass value before chemotherapy I and after chemotherapy III

\begin{tabular}{llll}
\hline Group & \multicolumn{2}{l}{ Mean \pm standard deviation } & \multirow{2}{*}{$\mathbf{p}^{*}$} \\
\cline { 2 - 3 } & $\begin{array}{l}\text { Before } \\
\text { chemotherapy I }\end{array}$ & $\begin{array}{l}\text { After } \\
\text { chemotherapy III }\end{array}$ \\
\hline BOM-cisplatin & $80.32 \pm 47.64$ & $44.81 \pm 31.34$ & 0.038 \\
BOM-carboplatin & $21.64 \pm 12.14$ & $16.78 \pm 14.18$ & 0.053 \\
\hline
\end{tabular}

Group BOM cisplatin: Based on statistical analysis as shown in Table 7, there is a significant difference of tumour mass value before chemotherapy I and after chemotherapy III $(* \mathrm{p}<0.05)$. The tumour-mass value decrease from 80.32 to 44.81 after third chemotherapy. Group BOM carboplatin: Based on statistical analysis as shown in Table 7, there is no significant difference of tumour mass value before chemotherapy I and after chemotherapy III $\left({ }^{*} \mathrm{p}>0.05\right)$. The tumourmass value decrease from 21.64 to 16.78 after third chemotherapy. BOM: Bleomycin vincristine mitomycin 
Table 8: Result of the difference paired t-test data of antigen SCC value before chemotherapy I and after chemotherapy III

\begin{tabular}{llll}
\hline Group & \multicolumn{2}{l}{ Mean \pm Standard deviation } & \multirow{2}{*}{$\mathbf{p}^{*}$} \\
\cline { 2 - 3 } & $\begin{array}{l}\text { Before } \\
\text { chemotherapy I }\end{array}$ & $\begin{array}{l}\text { After } \\
\text { chemotherapy III }\end{array}$ \\
\hline BOM-cisplatin & $21.67 \pm 33.62$ & $18.82 \pm 33.06$ & 0.655 \\
BOM-carboplatin & $13.58 \pm 12.07$ & $15.36 \pm 35.84$ & 0.861 \\
\hline
\end{tabular}

Group BOM cisplatin: Based on statistical analysis as shown in Table 8, there is no significant difference of antigen SCC value before chemotherapy I and after chemotherapy III $\left({ }^{*} p>0.05\right)$ ) ). The SCC value decrease from 21.67 to 18.82 after third chemotherapy. Group BOM carboplatin: Based on statistical analysis as shown in Table 8, there is no significant difference of antigen SCC value before chemotherapy I and after chemotherapy III $\left({ }^{*} \mathrm{p}>0.05\right)$. The SCC value increase from 13.58 to 15.36 after third chemotherapy. SCC: Squamous cell carcinoma

received BOM-carboplatin. BUN mean value before chemotherapy I was $10.55 \mathrm{~g} / \mathrm{dl}$ and became $9.56 \mathrm{~g} / \mathrm{dl}$ after chemotherapy III. Creatinine serum mean value before chemotherapy I was $2.63 \mathrm{~g} / \mathrm{dl}$ and became $0.90 \mathrm{~g} / \mathrm{dl}$ after chemotherapy III.

An increase in BUN and creatinine serum value of patients receiving BOMcisplatin indicates that a toxic effect is produced by the use of cisplatin in patients. One of the cisplatin side effects is nephrotoxicity that can result in kidney damage. The mechanism of cisplatin nephrotoxicity is an accumulation of cisplatin in kidney cells, cisplatin biotransformation in the kidney, and apoptosis of kidney cells by cisplatin [7]. So that it can be concluded that the use of cisplatin has a larger effect of kidney disorders, compared with carboplatin. One research also uses cisplatin in treating cancer shown that 349 patients who given cisplatin (doses $15-120 \mathrm{mg} / \mathrm{m}^{2}$ ) in the first cycle chemotherapy caused nephrotoxicity with the percentage $13.7 \%$. Nephrotoxicity shown with increasing levels of serum creatinin as many as 1.5 times after 4-7 days after injection [19].

\section{Effectiveness parameters}

Parameters that are often used for the evaluation of the chemotherapy effectiveness in cervical cancer are SCC antigens and tumormass $[20,21]$. SCC antigen is the tumor marker most commonly used for cervical cancer where the concentration of SCC antigens found, correlate with stadium tumor, tumor size, tumor residue after treatment, a resurgence of cancer in patients with squamous cell cervical cancer [22]. Tumor-mass has an important role to determine the prognosis of cervical cancer, and it is a clinical marker to determine stadium for cervical cancer [20]

According to statistical analyses as shown in Tables 7 and 8, using the difference paired t-test of 12 patients who received chemotherapy BOMcisplatin there is no significant difference in the SCC antigens value $\left({ }^{*} \mathrm{p}=0.655\right)$ before chemotherapy I and after chemotherapy III $\left({ }^{*} \mathrm{p}>0.05\right)$, there is a significant difference in the tumour-mass $\left({ }^{*} \mathrm{p}=0.038\right)$ before chemotherapy I and after chemotherapy III $\left({ }^{*} \mathrm{p}<0.05\right)$. For 9 patients who received chemotherapy BOM-carboplatin as shown in Tables 7 and 8 obtained the result that there is no significant difference of Antigen SCC value $\left({ }^{*} \mathrm{p}=0.861\right)$ and tumour-mass $\left({ }^{*} \mathrm{p}=0.053\right)$ before chemotherapy I and after chemotherapy III $\left({ }^{*} \mathrm{p}>0.05\right)$.

Tumor-mass significant difference that occurs in patients after undergoing chemotherapy BOM-cisplatin shows that there is cancer cells response after receiving chemotherapy. Decrease in patients' tumor mass occurred because chemotherapy causes shrinkage mass tumor to cell size to be normal [23]. Similar research shows that a tumor mass shrinkage by up to $80 \%$ after undergoing neoadjuvan chemotherapy in patient with breast cancer [24].

Statistically, there are no significant difference of SCC antigen and tumor-mass on patients after undergoing chemotherapy BOMcarboplatin, but clinically there were declines in tumor-mass and increases in SCC antigens value. Before chemotherapy, I tumor-mass mean value was 80.32 and after chemotherapy III became 44.81 shows that there is a chemotherapy response on the tumor-mass although it is not significant. While the increase in SCC antigens value after undergoing chemotherapy showed resistance cancer cells or cancer tends to become progressive [25]. In addition, the use of chemoradiation in cervical cancer SCCs also shows the increase in the value of SCC antigens. That indicates the recurrence in patients after undergoing chemoradiation [26].

\section{CONCLUSION}

The use of combination BOM-cisplatin can be said to be effective by the change of patients' tumor-mass after undergoing chemotherapy. The combination BOM-carboplatin is not effective because there were no changes in patients' tumor-mass and patients' levels of antigen SCC, and has toxic effects on patient's blood after undergoing chemotherapy.

\section{REFERENCES}

1. Florento L, Matias R, Tuaño E, Santiago K, Dela Cruz F, Tuazon A Comparison of cytotoxic activity of anticancer drugs against various human tumor cell lines using in vitro cell-based approach. Int J Biomed Sci 2012;8(1):76-80.

2. World Health Organitation. Cancer Control Knowledge into Action. Geneva: World Health Organitation; 2007.

3. Choi JS, Koren G, Nulman I. Pregnancy and isotretinoin therapy CMAJ 2013;185(5):411-3.

4. Taneja A, Rajaram S, Agarwal S, Singh KC, Sahni S, Goel N. Quick cycle neoadjuvant chemotherapy in squamous cell carcinoma of cervix. Indian J Pharmacol 2005;37(5):320-4

5. Yin M, Hou Y, Zhang T, Cui C, Zhou X, Sun F, et al. Evaluation of chemotherapy response with serum squamous cell carcinoma antigen level in cervical cancer patients: A prospective cohort study. PLoS One 2013;8(1):e54969.

6. Buda A, Fossati R, Colombo N, Fei F, Floriani I, Gueli Alletti D, et al. Randomized trial of neoadjuvant chemotherapy comparing paclitaxel, ifosfamide, and cisplatin with ifosfamide and cisplatin followed by radical surgery in patients with locally advanced squamous cell cervical carcinoma: The SNAP01 (studio neo-adjuvante portio) Italian collaborative study. J Clin Oncol 2005;23(18):4137-45.

7. Miller RP, Tadagavadi RK, Ramesh G, Reeves WB. Mechanisms of cisplatin nephrotoxicity. Toxins (Basel) 2010;2(11):2490-518.

8. Indonesia Departement of Health. Guidelines for the Interpretation of Clinical Data. Jakarta: Indonesia Departement of Health; 2012.

9. Wang $\mathrm{J}, \mathrm{Lu} \mathrm{Z}, \mathrm{Au} \mathrm{JL}$. Protection against chemotherapy-Induced alopecia. Pharm Res 2006;23(11):2505-14.

10. Ariawati K, Endang WD, Gatot D. Toxixity of chemotherapy, lymphoblastic leukemia acute in induction and prophylaxis phase of CNS with 1 gram methotrexate. Faculty of Medicine, Udayana University; 2007.

11. Testa, JN. Heardy, Molineux G. Long term bone marrow damage after cytotoxic treatment: Stem cells and microenvironment. In: Testa NG, Gale RP, editors. Hematopoiesis. Vol. 82. New York, NY, USA: Marcel Dekker; 1988. p. 51-6.

12. Liu W, Zhang CC, Li K. Prognostic value of chemotherapy-Induced leukopenia in small-cell lung cancer. Cancer Biol Med 2013;10(2):92-8

13. Park TK, Kim SN, Kim SW, Kim GE, Suh CO. Concurrent chemotherapy and radiotherapy in invasive cervical cancer patients with high risk factor. J Korean Med Sci 2000;15(4):436-41.

14. Thapa BR, Walia A. Liver function tests and their interpretation. Indian J Pediatr 2007:74(7):663-71.

15. Rauf S, Prefitri AM, Irianta T, Chalid MT. The role of squamous cell carsinoma and carsino embryonic antigen in determining the clinical response of advanced stage cervical cancer patients undergoing bleomycin, oncovin, mitomycin-c, cisplatin chemotherapy. Oncology Division, Departement of Obstetrics and Gynecology, Medical Faculty Hasanuddin University and Obstetrics and Gynecology Wahidin Sudirohusodo Hospita, Makasar; 2006.

16. Joshi M, Sodhi KS, Pandey R, Singh J, Goyal S, Prasad S, et al. Cancer chemotherapy and hepatotoxicity: An update. IAJPR 2014;4(6):2976-84.

17. Hruban RH, Sternberg SS, Meyers P, Fleisher M, Menendez-Botet C, Boitnott JK. Fatal thrombocytopenia and liver failure associated with carboplatin therapy. Cancer Invest 1991;9(3):263-8.

18. Indonesia Departement of Health. Guidelines for the Interpretation of 
Clinical Data. Jakarta: Indonesia Departement of Health; 2009.

19. Kobayashi R, Suzuki A, Matsuura K, Yamada N, Nakano M, Deguchi T, et al. Risk analysis for cisplatin-induced nephrotoxicity during first cycle of chemotherapy. Int J Clin 2016;9(2):3635-41.

20. Yoon SM, Shin KH, Kim JY, Seo SS, Park SY, Moon SH, et al. Use of serum squamous cell carcinoma antigen for follow-up monitoring of cervical cancer patients who were treated by concurrent chemoradiotherapy. Radiat Oncol 2010;5:78.

21. Pecorelli S. Revised FIGO staging for carcinoma of the vulva, cervix, and endometrium. Int J Gynaecol Obstet 2009;105(2):103-4.

22. Sturgeon CM, Diamandis E. Laboratory Medicine Practice Guidelines: Use of Tumor Markers in Liver, Bladder, Cervical, and Gastric Cancers. Washington: American Association for Clinical Chemistry; 2010 p. 25-31.
23. Irawan A. Cautious Tumor and Cancer. Bandung: Carya Remaja; 2001. p. 1-5.

24. Liu K, Wang GB, Cheng B, Qiu DB. Clinical comparison of GC regimen (gemcitabine and cisplatin) versus FEC regimen (fluorouracil, epirubicin, and cyclophosphamide) as neoadjuvant chemotherapy for breast cancer. Ai Zheng 2007;26(4):427-30.

25. Gaarenstroom KN, Kenter GG, Bonfrer JM, Korse CM, Van de Vijver MJ, Fleuren GJ, et al. Can initial serum cyfra 21-1, SCC antigen, and TPA levels in squamous cell cervical cancer predict lymph node metastases or prognosis? Gynecol Oncol 2000;77(1):164-70.

26. Micke O, Bruns F, Schäfer U, Prott FJ, Willich N. The impact of squamous cell carcinoma (SCC) antigen in patients with advanced cancer of uterine cervix treated with (chemo-) radiotherapy. Anticancer Res 2005;25(3A):1663-6. 